\title{
Comparison of clinical manifestation of dengue fever in Bangladesh: an observation over a decade
}

\author{
Mohammad Jahid Hasan ${ }^{*}$ (D), Tamanna Tabassum", Mohiuddin Sharif², Md. Abdullah Saeed Khan', \\ Akhi Roy Bipasha', Ariful Basher ${ }^{3}$, Mohammad Rafiqul Islam ${ }^{4}$ and Mohammad Robed Amin²
}

\begin{abstract}
Background: The clinical presentation of dengue fever had been observed to change with time since its first outbreak in 2000 in Bangladesh. This report showed the clinical presentation of the 2019 outbreak in Bangladesh along with its comparison to previous outbreaks witnessed in this region.

Methods: This hospital-based cross-sectional study was conducted in one of the largest tertiary care hospitals in Dhaka city. A total of 553 laboratory-confirmed and 194 probable dengue cases were interviewed. The clinical manifestation of the confirmed cases of the current outbreak was compared with three of the outbreak reports retrieved from the databases. R version 3.6.3 was used for data analysis.

Results: Among the confirmed cases, two-thirds were male (63.2\%) and the average age was 27( \pm 11$)$ years. Positive tests for NS1 and IgM were present in $99.6 \%(n=525 / 527)$ and $82.6 \%(n=38 / 46)$ of the cases, respectively. Thrombocytopenia was present in $66.1 \%$ of cases. Fever (100\%) was common for all. Gastrointestinal (GIT) features, including abdominal pain (86.5\%), anorexia and/or vomiting (69.6\%), and Diarrhea (> 3 motions/day) (26.2\%) were more frequent than typical rash and other pain symptoms. Hypotension was present in approximately a quarter of patients (25\%). GIT features (anorexia, nausea, and/or vomiting) and hypotension were more common among adult participants while bleeding manifestation (melena and vaginal bleeding, $p=0.009 \& 0.032$ ) was more frequent in pediatric patients. Compared to outbreaks of 2008, 2016, and 2018, increasing trends in GIT symptoms e.g. anorexia, abdominal pain, and diarrhea were observed. While a negative trend in hemorrhagic manifestations (skin rash, melena, and conjunctival hemorrhage/hemorrhagic sclera) and arthralgia/joint pain were found.
\end{abstract}

Conclusion: The present outbreak was noticeably characterized by GIT symptoms and hypotension in addition to the typical clinical features like rash and pain symptoms. An increasing trend in GIT features and decreasing trend in hemorrhagic manifestations was noted over the last decade of dengue outbreaks.

Keywords: Dengue outbreak, Shift of paradigm, Dengue fever, Dengue hemorrhagic fever, Dengue shock syndrome

*Correspondence: dr.jahid61@gmail.com; jahid@pircc.org

1 Pi Research Consultancy Center, Dhaka, Bangladesh

Full list of author information is available at the end of the article

\section{Background}

Dengue fever (DF) is an arthropod-borne viral disease that affects over 100 million cases worldwide [1, 2]. Bangladesh is a country that is most adversely affected by dengue almost every year [3]. The first official outbreak of dengue was reported in 2000 with a total of 5551 cases and 93 reported deaths [4]. Since then, several incidents 
of the outbreak were observed over the decade. An estimate suggested the reported dengue cases were 2430 (in 2001), 6232 (in 2002), 3934 (in 2004), 3162 (in 2015), 6060 (in 2016), and 10,148 (in 2018) [3]. In 2019, the country witnessed its largest outbreak in history with $>100,000$ confirmed cases and 120 deaths [5]. In 2020, amidst the pandemic, a total of 1026 confirmed cases were reported by the Directorate General of Health in Bangladesh [6].

The clinical manifestations of dengue infection range from mild febrile illness (i.e., DF) to severe hemorrhagic disease (i.e., DHF) and Dengue Shock Syndrome (DSS) $[7,8]$. Classical dengue patients usually present with fever, arthralgia, myalgia, retro-orbital pain, and rash. Dengue cases also present with hemorrhagic manifestation (e.g. sub-conjunctival hemorrhage, petechiae, epistaxis, etc.) with or without shock [7]. Respiratory symptoms, gastrointestinal disorders, reduced platelet count, and abnormal liver function tests were also evident as presenting features of dengue now a day [9]. A temporal variation in the frequency of different clinical manifestations can be noted over the decade since the first outbreak [10-14] For example the outbreak of 2000 and 2002 were characterized by high-grade fever with typical purpuric rash, break-bone body ache, and thrombocytopenia [13, 15], whereas in 2010 [12] and 2018 [11] outbreaks, predominant manifestations were fever, gastrointestinal symptoms and bleeding manifestation with normal platelet counts. Frequent transitions to plasma leakage leading to respiratory distress syndrome and organ dysfunction were more commonly observed and were considered a predicting factor of higher case fatality $[12,13]$. A few other reports agreed with the preceding result $[16,17]$. Shifting of serotypes (DEN-1, 2, 3, and 4) across the outbreaks and re-infection were hypothesized as an underlying cause of this change in clinical manifestation $[18,19]$. Detailed serotype data in the individual outbreak are currently lacking. However, DEN-3 has isolated the outbreaks before $2002[1,8]$, while DEN-1 and 2 were the prevalent strain in the outbreaks between 2013 and 2016 [18]. Re-emergence of the DEN-3 was noticed in 2017 and DEN-3 and DEN-4 were more commonly found in recent times [19]. Even, co-detection of dengue serotypes in multiple combinations (DEN-2 \& DEN-3 or DEN-1 \& DEN-3 or DEN-1, 2 \& 3) were observed in several cases in the last two outbreaks. Cross-reactivity of the antibodies therefore might be the reason for severe dengue infection as well as the changed pattern of clinical presentation of the dengue cases in recent time.

Dengue is an emerging public health problem in Bangladesh. From the clinical point of view, identification of shifts in the clinical pattern will improve case-finding and clinical management. Thus, this study aimed to give an insight into the shifting of clinical manifestation of dengue cases in Bangladesh.

\section{Methods}

Here, we initially performed a cross-sectional analysis of the clinical manifestations of dengue during the period of July 2019 to December 2019. Subsequently, we compared these findings with the findings of those studies that were undertaken in similar hospital settings and which included similar types of patients. This was done with the objective of analyzing the changes of the clinical manifestations of the dengue over different time periods.

The initial descriptive cross-sectional study was conducted at the inpatient Department of Medicine, 'Dengue Corner' of Sheikh Hasina Burn and Plastic Surgery Institute and Department of Pediatrics in Dhaka Medical College Hospital (DMCH) during the dengue outbreak of 2019. Sample size was calculated from the following formula: $n=\frac{z^{2} p(1-p)}{d^{2}}$, where, $\mathrm{z}=$ standard normal deviate, set at 1.96 at for $95 \%$ confidence level, $\mathrm{p}=$ estimated prevalence of infection, and $\mathrm{d}=$ margin of error (0.05). Considering unknown (50\%) prevalence and using $5 \%$ margin of error, our calculated sample size was 385. However, we included 747 patients in this study. Details of the methods are given below. The study adheres to the STROBE guideline for cross-sectional study and available in Additional file 1: Table 1.

To compare the clinical manifestation of different dengue outbreaks over the last two decades, we sought studies having three criteria: (i) conducted in the same settings (DMCH), (ii) study followed same study designs (cross-sectional), and (iii) reported dengue outbreak of Bangladesh other than 2019. Four databases (PubMed, BanglaJol, Scielo, and Google Scholar) were searched to find out outbreak reports with keywords 'Dengue' AND 'Bangladesh'. Bibliographic search and personal communication were also used to find out published and unpublished works which documented previous outbreaks within the periods of the years 2000-2019. Database searches were limited up to December 2019. Details of the searching strategy are available in Additional file 1: Fig. 1. Studies that were conducted in Dhaka Medical College Hospital and reported an outbreak of dengue in the different periods were selected for comparison. Finally, three original articles that fulfilled the criteria (i.e. Outbreak report of 2008 by Arif et al. [13], 2016 by Pervin et al. [20]; 2018 by Sultana et al. [21]) were used for data extraction and comparison with the latest outbreak of 2019. The collective variables data from each of the above-mentioned reports were compared, specifically for differences in clinical manifestations. The study characteristics are described in Additional file 1: Table 2. Details 
of statistical comparison are mentioned in the statistical analyses section.

\section{The rationale of study site selection}

Dhaka Medical college hospital, situated at $23.7257^{\circ} \mathrm{N}$, and $90.3971^{\circ} \mathrm{E}$, [22] is one of the largest tertiary care hospitals situated in the capital of Dhaka city. According to the Health bulletin published by the Directorate general of health services, the hospital dealt with 935,876 outpatient visits, 172,343 inpatients admission, and 462,438 emergency ward attendants in the year 2017 [23]. The hospital provided care for various health problems for adults, children, and the geriatric population. In the period of outbreak, it operates a dengue corner equipped with a multidisciplinary team specialized in the management of dengue during the outbreak. As a result, the hospital receives referrals and admission from nearby districts and cities of the country. In addition, the government pays a subsidy to keep the centers going. Hence, the center is almost always considered the prime referral center as well as a nationally representative hospital of the country [24].

\section{Procedure of data collection in $\mathbf{2 0 1 9}$ dengue outbreak} Clinically suspected cases of dengue were initially approached for inclusion. A person living in or traveling to the dengue-endemic zone with fever along with any two of the following symptoms-nausea/or vomiting, rash, aches and pains, positive tourniquet test, leucopenia $\left(<4000 / \mathrm{mm}^{3}\right)$, and any warning signs (abdominal pain/tenderness, persistent vomiting, clinical fluid accumulation, mucosal bleed, lethargy/restlessness, liver enlargement $>2 \mathrm{~cm}$, increase in hematocrit with a rapid decrease in platelet count)-was considered a probable dengue case. On the other hand, characteristics of the probable dengue cases along with a positive NS1 antigen $(\mathrm{Ag})$ and/or anti-dengue IgM test were referred to as confirmed dengue cases. This approach was based on the guidance of 'The national guideline for clinical management of Dengue Syndrome, Bangladesh 2018' [25]. Written informed consent was ensured before participation and. In case of minors, written consent was taken from the parents or legal guardians of the parents. The study population was free to give information during the study and no benefits were offered for participation. Patients not providing consent or having co-infection were also excluded from the study. A detailed case record form was prepared for data collection and used throughout the data collection period. Demographic information e.g. age, gender, residence, occupation was collected. Clinical characteristics and laboratory investigations were also sought and recorded. Complete blood count (CBC) was routinely evaluated for all patients with an automated hematology analyzer, Mindray|BC-5150. Leukopenia was defined as a total WBC count of $<4000 / \mathrm{mm}^{3}$. Thrombocytopenia was defined as a total platelet count of $<100,000 / \mathrm{mm}^{3}$. For the detection of non-structural viral protein (NS1 Ag) commercially available kits (Rapid test kit, In Bios Int USA) were used. The IgM antibody and IgG antibody detection in blood samples were carried out using a commercially available kit supplied by DRG International (USA). Raised alanine aminotransferase (ALT) and aspartate aminotransferase (AST) were defined as $>50 \mathrm{IU} / \mathrm{L}$ in both cases. Raised bilirubin was considered when values raised $>2 \mathrm{mg} / \mathrm{dl}$. Selecta PRO-M auto analyzer was used to estimate serum bilirubin, ALT, and AST. All laboratory investigation was performed in the laboratory of the DMCH. However, blood tests were requested based on the condition of the patients assessed by study physicians and differed from case to case. Clinical information was collected from the history and physical examination of the patients. Record review was done to collect the report of the investigations. A total of 793 cases were approached, and 36 patients were excluded due to not providing consent, or having coinfection or critical illness. Furthermore, 10 cases were excluded due to incomplete data ( $>50 \%$ of variables missing information). More details are described in Additional file 1: Fig. 2. Finally, a total of 747 cases (553 confirmed and 194 probable dengue cases) were interviewed. In this study, only confirmed dengue cases are described and used for comparison.

\section{Ethics statement}

The study protocol was reviewed and received approval by the Ethical Review Committee (ERC) of Dhaka Medical College (DMC) in 2019 with registration no: MEUDMC/ECC/2019/251. The outbreak reports used to compare the clinical characteristics of dengue patients were retrieved from the database, hence waived for ethical review.

\section{Data extraction for comparison of the outbreak}

We extracted the proportion of available symptoms from selected outbreak reports. Following extraction, we tabulated the information using a Microsoft Excel spreadsheet.

\section{Statistical analyses}

Collected data were sorted and cleaned with necessary modifications. Missing values were managed by subtracting the data from the final data set. No mean imputation was made. To describe the characteristics of the confirmed dengue cases of the 2019 outbreak, we used mean \pm standard deviation, and percentage when appropriate. Differences in clinical characteristics between 
adults and children were compared using the Pearson Chi-square $\left(\chi^{2}\right)$ or Fisher's exact test for categorical variables, or the Student $t$-test or the Mann-Whitney $U$ test for continuous variables. Changing patterns of each symptom over the decade were tested by CochranArmitage-test. The proportion of different outbreaks were considered. Here, symptoms reported by at least 3 outbreaks at any point in the period were considered for trend analysis. A negative slope indicates the decreasing proportion of symptoms and a positive slope indicates a positive linear trend and explains the increasing symptoms over the period. For statistical testing, statistical software $\mathrm{R}$ version 3.6.3 was used, and $\mathrm{p}$-values of $<0.05$ were considered statistically significant.

\section{Results}

A total of 747 suspected dengue cases were approached and 553 cases were confirmed by laboratory investigation and 194 were designated as probable cases. Differences between the confirmed and probable dengue cases are available in Additional file 1: Tables 3 and 4.

Among the confirmed cases ( $\mathrm{n}=553), 63.2 \%$ (347) were male. Predominant age group was $21-30$ years (37.7\%) [age range 3-85 years]. The mean age of the total population was $27( \pm 11)(\mathrm{SD})$ years and $38.2 \%$ reporting a history of travel to an endemic zone (Table 1).

Fever was present in all patients (100\%). Other common symptoms were abdominal pain (41.6\%), nausea/ vomiting (69.6\%), and severe headache $(62.7 \%)$. Melena (5.4\%) and gum bleeding (3.6\%) were the two most common bleeding manifestations observed. Among the presenting signs, the most common were hypotension (25\%), low pulse pressure $(22.1 \%)$, and positive tourniquet test (10.5\%). Approximately, $5 \%$ of patients showed skin rash during admission. The vital signs of the cohort are shown in Table 2.

Table 3 presents the investigation findings of the confirmed cases. Out of 527 patients, 525 (99.6\%) were found positive for Dengue NS1 antigen, and out of 46 patients, 38 (82.6\%) were positive for Dengue IgM antibody. Approximately, 66\% had thrombocytopenia, 29\% had leucopenia. Serum bilirubin, ALT, and AST were found to be high in $13 \%, 50 \%$, and $67.4 \%$ of patients, respectively.

There were 131 missing values in the age of the participants. To compare the clinical characteristics between pediatric and adults, we used data from 422 patients (Paediatric-96 vs adult-326). It was observed that gastrointestinal features e.g. anorexia $(p=0.028)$, nausea, and vomiting $(\mathrm{p}=0.029)$ were more frequent than adults while hypotension $(\mathrm{p}=0.003)$ was more prevalent among adults. Bleeding features e.g. melena $(\mathrm{p}=0.009)$, and vaginal bleeding (0.032) were commonly found in
Table 1 Demographic characteristics of study population in outbreak 2019

\begin{tabular}{ll}
\hline Variables & $\mathbf{n}(\%)$ \\
\hline Age $(\mathrm{n}=422)$ & \\
$<10$ years & $7(1.7)$ \\
$11-20$ years & $134(31.8)$ \\
$21-30$ years & $159(37.7)$ \\
$31-40$ years & $77(18.2)$ \\
$41-50$ years & $29(6.9)$ \\
51-60 years & $9(2.1)$ \\
61-70 years & $5(1.2)$ \\
$>70$ years & $2(0.5)$ \\
Mean ( \pm SD) & $27( \pm 11)$ \\
Sex (n=549) & \\
Male & $347(63.2)$ \\
Female & $202(36.8)$ \\
Occupation $(\mathrm{n}=269)$ & \\
Student & $105(39)$ \\
Housewife & $84(31.2)$ \\
Service holder & $36(13.4)$ \\
Businessman & $26(9.7)$ \\
Farmer & $5(1.9)$ \\
Hawker & $4(1.5)$ \\
Driver & $3(1.1)$ \\
Govt. service & $2(0.7)$ \\
Teacher & $2(0.7)$ \\
Rickshaw puller & $1(0.4)$ \\
Unemployed & $1(0.4)$ \\
H/o travelling in endemic zone $(\mathrm{n}=453)$ & $173(38.2)$ \\
\hline &
\end{tabular}

Decimal number were rounding up with nearest one

the pediatric population compared to adults. More is described in Table 4.

A comparison of clinical manifestations among four outbreaks is described in Table 5. The proportion of males was persistently more in all outbreaks but the recent outbreak is characterized by the presence of more female cases than the previous outbreaks. Trend analysis supports contracted male presence over time and it is statistically significant $(\mathrm{p}=0.0073$, slope: -0.0552$)$. An increasing trend of abdominal symptoms including anorexia, abdominal pain, and diarrhea was observed in recent outbreaks ( $\mathrm{p}<0.05$ and slope: + ve for all cases) whereas the decreasing trend is noticed in terms of hemorrhagic manifestations including skin rash $(\mathrm{p}=0.003$, slope: -0.04$)$, melena $(p=0.5421$, slope: -0.0105$)$ or conjunctival hemorrhage/hemorrhagic sclera $(\mathrm{p}=0.4131$, slope: - 0.0213) compared to the previous outbreak. Classic symptoms like headache are persistently common in all outbreaks and an increasing trend is visible ( $\mathrm{p} \leq 0.0001$, slope: 0.1261$)$. Significant decline trend 
Table 2 Clinical characteristics of confirmed dengue cases $(n=553)$

Presenting symptoms

Total $(n=553)$

n (\%)

Fever

$553(100)$

Chill (associated with fever)

$52(9.4)$

Shivering (associated with fever)

$20(3.6)$

Sweating

$123(22.2)$

Severe headache

$347(62.7)$

Retroorbital pain

$216(39.1)$

Redness of eye

$67(12.1)$

Back pain

58 (10.5)

Neck pain

$39(7.1)$

Sore throat

$9(1.6)$

Rash

$25(4.5)$

Joint pain

$25(4.5)$

Anorexia

$210(38.0)$

Nausea

$385(69.6)$

Vomiting

$385(69.6)$

Diarrhea (> 3 motions/day)

$145(26.2)$

Abdominal pain

$230(41.6)$

Cough

$30(5.4)$

Respiratory distress

$25(4.5)$

Convulsion

$1(0.2)$

Decreased urine output

$13(2.4)$

Pattern of bleeding manifestations

Blood in stool (melena)

$30(5.4)$

Gum bleeding

$20(3.6)$

Vaginal bleeding

$10(1.8)$

Epistaxis

$9(1.6)$

Hematuria

$3(0.5)$

\section{Presenting signs}

Hypotension

$135(25.0)$

Low pulse pressure

$60(22.1)$

Tourniquets test positive

$12(10.5)$

Skin rash

$25(4.5)$

Dehydration

$31(7.8)$

Anemia

$26(4.7)$

Jaundice

$4(0.72)$

Edema

$1(0.18)$

Pleural effusion

$10(1.8)$

Ascites

$7(1.26)$

Splenomegaly

$1(0.18)$

Hepatomegaly

$3(0.54)$

\section{Vital signs}

Mean \pm SD

$$
\begin{aligned}
& \text { Pulse (/min) } \\
& \text { SBP }(m m H g)
\end{aligned}
$$

$97 \pm 11$

DBP $(\mathrm{mmHg})$

$93 \pm 15$

Respiratory rate (/min)

$66 \pm 12$

Temperature $\left({ }^{\circ} \mathrm{F}\right)$

$18 \pm 4$

$100 \pm 1$

$S B P$ systolic blood pressure; $D B P$ diastolic blood pressure 
Table 3 Investigation findings of situ population of outbreak 2019

\begin{tabular}{|c|c|}
\hline Serological tests & n (\%) \\
\hline \multicolumn{2}{|l|}{ NS1 antigen $(n=527)$} \\
\hline Positive & 525 (99.6) \\
\hline Negative & $2(0.4)$ \\
\hline \multicolumn{2}{|l|}{ Dengue IgM antibody $(n=46)$} \\
\hline Positive & $38(82.6)$ \\
\hline Negative & $8(17.4)$ \\
\hline \multicolumn{2}{|l|}{ Dengue $\lg G$ antibody $(n=32)$} \\
\hline Positive & $19(59.4)$ \\
\hline Negative & $13(40.6)$ \\
\hline \multicolumn{2}{|l|}{$\mathrm{HCT}(\mathrm{n}=344)$} \\
\hline High (>48\%) & $17(3.9)$ \\
\hline Normal & $418(96.1)$ \\
\hline \multicolumn{2}{|l|}{ Hemoglobin $(n=336)$} \\
\hline $\operatorname{Low}(<11 \mathrm{~g} / \mathrm{dl})$ & $38(11.3)$ \\
\hline Normal & $298(88.7)$ \\
\hline \multicolumn{2}{|l|}{ Leucopenia $(n=272)$} \\
\hline Present $\left(<4000 / \mathrm{mm}^{3}\right)$ & $79(29)$ \\
\hline Absent & $193(71)$ \\
\hline \multicolumn{2}{|l|}{ Thrombocytopenia $(n=384)$} \\
\hline Present $\left(<150,000 / \mathrm{mm}^{3}\right)$ & $254(66.1)$ \\
\hline Absent & $130(33.9)$ \\
\hline \multicolumn{2}{|l|}{ Serum bilirubin $(n=23)$} \\
\hline $\operatorname{High}(>2 \mathrm{mg} / \mathrm{dl})$ & $3(13)$ \\
\hline Normal & $20(87)$ \\
\hline \multicolumn{2}{|l|}{$\operatorname{ALT}(n=146)$} \\
\hline High (> 50 U/L) & $73(50)$ \\
\hline Normal & $73(50)$ \\
\hline \multicolumn{2}{|l|}{ AST $(n=132)$} \\
\hline High (>50 U/L) & $89(67.4)$ \\
\hline Normal & $43(32.6)$ \\
\hline
\end{tabular}

is observed in arthralgia/joint pain $(\mathrm{p}=0.0002$; slope: -0.0781 ) over the times while opposite trend is noticed for retro-orbital pain/eye ache are $(p=0.0641$, slope: $0.0384)$.

\section{Discussion}

Bangladesh is frequently facing outbreaks of dengue since its emergence in 2000. In 2019 the country faced its worst outbreak in history with infection reaching all parts of the country [26]. Our study revealed that affected persons were mostly young and adolescent males. A characteristic presence of gastrointestinal symptoms alongside the usual general features was a notable finding of this outbreak.

Dengue patients typically present with the triad of fever, pain, and rash. However, gastrointestinal and
Table 4 Clinical characteristics adult and child dengue cases $(n=422)$

\begin{tabular}{|c|c|c|c|}
\hline Presenting symptoms & $\begin{array}{l}\text { Pediatric } \\
\mathrm{n}(\%) \\
(\mathrm{n}=96)\end{array}$ & $\begin{array}{l}\text { Adult } \\
n(\%) \\
(n=326)\end{array}$ & $p$ value ${ }^{* *}$ \\
\hline Fever & $96(100)$ & $326(100)$ & 1.0 \\
\hline Chill (associated with fever) & $14(14.6)$ & $28(8.6)$ & 0.118 \\
\hline Shivering (associated with fever) & $6(6.3)$ & $14(4.3)$ & 0.418 \\
\hline Sweating & $26(27.1)$ & $91(27.9)$ & 1.0 \\
\hline Severe headache & $62(64)$ & $168(51.5)$ & 0.016 \\
\hline Retroorbital pain & $34(35.4)$ & $82(25.2)$ & 0.034 \\
\hline Redness of eye & $11(11.5)$ & $26(8)$ & 0.306 \\
\hline Back pain & $13(13.5)$ & $32(9.8)$ & 0.346 \\
\hline Neck pain & $11(11.5)$ & $18(5.5)$ & 0.063 \\
\hline Sore throat & $1(1)$ & $4(1.2)$ & 1.0 \\
\hline Rash & $3(3.1)$ & $22(6.7)$ & 0.226 \\
\hline Joint pain & $9(9.4)$ & $16(4.9)$ & 0.137 \\
\hline Anorexia & $35(36.5)$ & $81(24.8)$ & 0.028 \\
\hline Nausea & $77(80.2)$ & $224(68.7)$ & 0.029 \\
\hline Vomiting & $77(80.2)$ & $224(68.7)$ & 0.029 \\
\hline Diarrhea (>3 motions/day) & $24(25)$ & $102(31.3)$ & 0.256 \\
\hline Abdominal pain & $40(41.6)$ & $122(37.4)$ & 0.45 \\
\hline Cough & $6(6.3)$ & $13(4)$ & 0.399 \\
\hline Respiratory distress & $2(2.1)$ & $19(5.8)$ & 0.184 \\
\hline Convulsion & $1(1)$ & $0(0)$ & 0.227 \\
\hline Decreased urine output $(n=16)$ & $4(4.2)$ & $7(2.1)$ & 0.469 \\
\hline \multicolumn{4}{|l|}{ Pattern of bleeding manifestations } \\
\hline Blood in stool (melena) & $12(12.5)$ & $16(4.6)$ & 0.009 \\
\hline Gum bleeding & $7(7.3)$ & 10(3.1) & 0.077 \\
\hline Vaginal bleeding & $5(5.2)$ & $4(1.2)$ & 0.032 \\
\hline Epistaxis & $4(4.2)$ & $3(0.9)$ & 0.50 \\
\hline Hematuria & $1(1)$ & $2(0.6)$ & 1 \\
\hline \multicolumn{4}{|l|}{ Presenting signs } \\
\hline Hypotension & $55(58.5)$ & 234(74.3) & 0.003 \\
\hline Low pulse pressure & $39(40.6)$ & $114(34.96)$ & 0.306 \\
\hline Tourniquets test positive & $2(2.08)$ & $10(3.06)$ & 0.726 \\
\hline Skin rash & $3(3.1)$ & $22(6.7)$ & 0.226 \\
\hline Dehydration & $4(4.16)$ & $24(7.36)$ & 0.345 \\
\hline Anemia & $1(1.04)$ & 1 (0.306) & 1.0 \\
\hline Jaundice & $0(0)$ & $4(1.22)$ & 0.310 \\
\hline Edema & $1(1.04)$ & $0(0)$ & 0.234 \\
\hline Pleural effusion & $2(2.08)$ & $6(1.84)$ & 1.0 \\
\hline Ascites & $3(3.1)$ & $2(2.08)$ & 0.091 \\
\hline Splenomegaly & $0(0)$ & $1(1.04)$ & 1.0 \\
\hline Hepatomegaly & $0(0)$ & $1(1.04)$ & 1.0 \\
\hline
\end{tabular}

Decimal number were rounding up with nearest one

**P-value estimated using chi-square test

bleeding manifestations might occur in variable proportions [27]. Previously, a severe form of infection was less frequent than the recent outbreaks in Bangladesh. This 
Table 5 Presenting symptoms of the dengue patients in 2019 outbreak with comparison of previous outbreak

\begin{tabular}{|c|c|c|c|c|c|c|}
\hline & $\begin{array}{l}\text { Outbreak } \\
2008\end{array}$ & $\begin{array}{l}\text { Outbreak } \\
2016\end{array}$ & $\begin{array}{l}\text { Outbreak } \\
2018\end{array}$ & $\begin{array}{l}\text { Outbreak } \\
2019\end{array}$ & Chi-square statistic & p value* \\
\hline Lead author & Arif et al. [20] & Pervin et al. [21] & Sultana et al. [22] & Current study & & \\
\hline Sample size & 55 & 40 & 350 & 553 & & \\
\hline Mean age (years) & & & 25 & 27 & & \\
\hline \multicolumn{7}{|l|}{ Sex: (\%) } \\
\hline Male & 83.63 & 62.5 & 68.57 & 63.2 & 7.1892 & $0.0073^{\beta}$ \\
\hline Female & 16.37 & 37.5 & 31.43 & 36.8 & & \\
\hline \multicolumn{7}{|l|}{ Clinical features (\%) } \\
\hline Fever & & 100 & 100 & 100 & & \\
\hline \multicolumn{7}{|l|}{ Pain pattern } \\
\hline Headache & 32.72 & 25 & 61.14 & 62.7 & 32.0649 & $<0.0001^{a}$ \\
\hline Myalgia/body ache & & 12.5 & 44 & & & \\
\hline Low back pain & & & 3.14 & 10.5 & & \\
\hline Retro-orbital pain/eye ache & 16.38 & 50 & 20.29 & 39.1 & 3.4292 & $0.0641^{£}$ \\
\hline Arthralgia/joint pain & 9.09 & 87.5 & 23.14 & 4.5 & 14.2545 & $0.0002^{\beta}$ \\
\hline Neck pain & & & & 7.1 & & \\
\hline \multicolumn{7}{|l|}{ Respiratory symptoms } \\
\hline Respiratory distress & & & & 4.5 & & \\
\hline Cough & & & & 5.4 & & \\
\hline \multicolumn{7}{|l|}{ Abdominal symptoms } \\
\hline Anorexia & 5.45 & 27.5 & & 38 & 29.3381 & $<0.0001^{a}$ \\
\hline Nausea & & 27.5 & & 69.6 & & \\
\hline Vomiting & 40 & 27.5 & & & & \\
\hline Diarrhoea & 3.63 & 25 & 5.14 & 26.2 & 8.9826 & $0.0027^{a}$ \\
\hline \multicolumn{7}{|l|}{ Abdominal distension } \\
\hline Abdominal pain & 1.81 & 30 & 32.86 & 41.6 & 143.39 & $<0.001^{a}$ \\
\hline \multicolumn{7}{|l|}{ Clinical signs } \\
\hline Pleural effusion & & & & 2.5 & & \\
\hline Ascites & & & & 1.8 & & \\
\hline Jaundice & & 12.5 & & 1 & & \\
\hline Skin rash & & 12.5 & 6 & 4.5 & 4.5205 & $0.0335^{\beta}$ \\
\hline \multicolumn{7}{|c|}{ Diff. types of hemorrhagic manifestation } \\
\hline Positive tourniquet test & 43.63 & & & 10.5 & & \\
\hline Melena & & 7.5 & 6.1 & 5.4 & 0.3717 & $0.5421^{€}$ \\
\hline Gum bleeding & & & & 3.6 & & \\
\hline Haematuria & & & & 0.5 & & \\
\hline Conj. Hge./hemorrhagic sclera & 16.36 & 20 & & 12.1 & 0.6699 & $0.4131^{\epsilon}$ \\
\hline \multicolumn{7}{|l|}{ Haematemesis } \\
\hline \multicolumn{7}{|l|}{ Haemoptysis } \\
\hline Epistaxis & & & & 1.6 & & \\
\hline Vaginal bleeding & & & & 1.8 & & \\
\hline Others & & & & 2.4 & & \\
\hline Less urine output & & & & 0.2 & & \\
\hline Hypotension & 70.9 & & & 25 & & \\
\hline \multicolumn{7}{|l|}{ Convulsion } \\
\hline \multicolumn{7}{|l|}{ Joint swelling } \\
\hline Lethargy & & 30 & & & & \\
\hline
\end{tabular}

Statistical analysis was performed for those variables who had data at least for 3 outbreak

* $p$-value was estimated by using Cochran-Armitage-test and $p$-value $<0.05$ was considered statistically significant

a Increasing and statistically significant trend present 
Table 5 (continued)

${ }^{\beta}$ Decreasing and statistically significant trend present

${ }^{\mathrm{E}}$ Increasing and statistically non-significant trend present

${ }^{\epsilon}$ Decreasing and statistically non-significant trend present

change is evident since 2018 [19] when the frequency of severe dengue cases increased. Shirin et al. proposed that a re-infection with DEN-3 serotype on the top of previously predominant DEN-1 and DEN-2 serotypes might be responsible for this increased severity [19] and was later confirmed by Ahsan et al. [28]. Consequently, the spectrum of clinical presentation of dengue might be facing a shift. This study aimed to explore this phenomenon.

Our exploration revealed that the 2019 outbreak was characterized by fever in all patients with the most common associated features being nausea and/or vomiting, severe headache, anorexia, and retro-orbital pain. These are the general features of dengue fever [25] and are well correlated with other similar studies [29-31]. But this year hemorrhagic presentation was relatively less common with approximately $5 \%$ having one or more bleeding manifestations. A study from a non-endemic zone of Bangladesh during the 2019 outbreak also reveals similar findings [32]. Our comparison of studies conducted in DMCH in 2008 [20], 2016 [21], 2018 [22], and the current study also reveals a decreasing proportion of bleeding manifestations (e.g., melena). Melena was the most common form of bleeding followed by gum bleeding in the current study. Moreover, skin rash was one of the prime features in previous outbreaks with a statistically significant decrease in recent outbreaks. In contrast studies in India showed a high prevalence of rash in 2015 [33] and $2018[34,35]$.

Another notable finding was a statistically increased frequency of diarrhea and abdominal pain over the last decade. Yung et al. [36] in Singapore observed that abdominal pain was more likely to occur in DEN-3 serotypes than DEN-1 and DEN-2. As the DEN-3 serotype was more prevalent in 2018 and 2019 outbreaks in Bangladesh [28], an increase in abdominal pain could be explained which, however, needs further verification through extensive serotype-specific clinical studies.

In the present study, the most common clinical sign was hypotension $(25.4 \%, \mathrm{n}=135)$ and low pulse pressure $(22.1 \%, n=60)$. A comparison of outbreaks concerning hypotension and pulse pressure was not possible due to the unavailability of data. But these indicators of plasma leakage show that at least one-quarter of the patients may have had dengue shock syndrome [37] in the current study. Interestingly this rapid development of hypotension and shock was not observed in previous outbreaks unlike in 2019, and it probably indicates a shift in severity of the disease.
As years were passing in Bangladesh, we got accustomed to a seasonal upsurge of a disease that seemed very benign at first with an occasional increase in severity. But the obvious change in presentation since the 2018 outbreak was marked by the increased number of cases and fatalities. As the clinical features are shifting physicians must be adept to learn about newer patterns. The epidemiological, environmental, virologi$\mathrm{cal}$, and vector dynamics are playing a pivotal role in this kind of shift. Hence besides clinical understanding, it would be prudent to go for studies related to virus, vector, environment, economics, and epidemiology.

During the dengue outbreaks from 2000 to 2019 patients with dengue, syndrome showed the varied presentation and the symptoms were nonspecific. Dengue virus interacts with host cells and causes the release of various cytokines and stimulates immunologic mechanisms, vascular endothelial changes, infiltration of mononuclear cells, and perivascular edema. Ascites, pleural effusion, and gall bladder edema from capillary leak syndrome are some of those features. But various atypical manifestations were also being added along the passage of time. As a result, Dengue viral infection has become a major public health issue in Bangladesh which is facing dengue outbreaks every year and mortality morbidity due to dengue is rising to an alarmingly high rate with each outbreak.

\section{Limitation of the study}

A major limitation of the study involved missing data due to the inability to systematically filled out by the study physicians. In addition, the overall number of children was small. Moreover, it was not possible to fully investigate all participants and to serotype the dengue cases, mostly due to lack of facility and funds. Lastly, a detailed feature-by-feature comparison of the different outbreaks was not possible due to inadequate details present in the available studies.

\section{Scope of the study}

Despite several limitations, our study was strong in that we reported a large number of cases during the 2019 dengue outbreak in Bangladesh and were able to analyze the changes of clinical manifestations across the outbreaks over time. Therefore, our results may aid in the adaptation and up-gradation of the national 
guideline and management strategies for future outbreaks in the country.

\section{Conclusion}

A comparison of clinical manifestation of dengue fever in Bangladesh over a decade showed that GIT symptoms were more prevalent than bleeding manifestations in recent times compared to the previous outbreak.

\begin{abstract}
Abbreviations
ALT: Alanine aminotransferase; AST: Aspartate aminotransferase; CBC: Complete blood count; DEN: Dengue serotype; DF: Dengue fever; DHF: Dengue hemorrhagic fever; DMCH: Dhaka Medical College Hospital; DSS: Dengue Shock Syndrome; ERC: Ethical Review Committee; GIT: Gastrointestinal; NS1 Ag: Non-structural viral protein 1.
\end{abstract}

\section{Supplementary Information}

The online version contains supplementary material available at https://doi. org/10.1186/s12879-021-06788-z.

Additional file 1: Figure 1. Searching details of the study underwent in $\mathrm{DMCH}$ and reporting dengue outbreak in Bangladesh. Figure 2. Flow chart of patient selection. Table 1. STROBE Statement-Checklist of items that should be included in reports of cross-sectional studies. Table 2. Study characteristics that not included for comparison. Table 3. Clinical characteristics of confirmed and probable dengue cases* $(n=747)$. Table 4. Laboratory findings of the confirmed and probable dengue cases of the study.

\section{Acknowledgements}

The author thanks "Pi Research Consultancy Center (www.pircc.org) for logistic aid, journal selection, and formatting support. Also, thanks to Sujan Rudra for the statistical review of the manuscript. Also thanks to Dr. Jannatul Fardous for her significant contributions of the manuscript. The research team is thankful to all patients who gave their valuable time and also the supporting staff of the hospitals.

\section{Authors' contributions}

Conception and design: MJH. Detailed outline of the study design: MJH, MS, MASK. Data acquisition and analysis: MJH, TT, MS, MASK, ARB, AB, MRI, and MRA. Data management was done by MS, TT, MASK, ARB, and MJH. Data interpretation was done by MJH, TT, MS, MASK, ARB, AB, MRI, and MRA. First draft of the manuscript was written by MJH, TT, MRA, ARB and MASK. Review and revision: MJH, TT, MS, MASK, ARB, AB, MRI, and MRA. All authors read and approved the final manuscript.

\section{Funding}

Self-Funded and the study received no support in the form of grants, equipment, drugs, or all of these.

\section{Availability of data and materials}

Data and materials supporting our findings in the manuscript will be shared on reasonable request (dr.jahid61@gmail.com).

\section{Declarations}

\section{Ethics approval and consent to participate}

The researchers were duly concerned about the ethical issues related to the study. Formal ethical clearance was taken from the Ethical Review Committee (ERC) of Dhaka Medical College (DMC). Informed written consent was taken from all of the participants. In case of minors, written consent was sought from the parent or legal guardians of the patients. Confidentiality was maintained properly.

\section{Consent for publication}

None.

\section{Competing interests}

The authors declare no competing interests.

\section{Author details}

${ }^{1}$ Pi Research Consultancy Center, Dhaka, Bangladesh. ${ }^{2}$ Department of Medicine, Dhaka Medical College and Hospital-2, Dhaka, Bangladesh. ${ }^{3}$ BSMMU,

OSD, Directorate General of Health Service, Dhaka, Bangladesh. ${ }^{4}$ Department of Medicine, Shaheed Suhrawardy Medical College, Dhaka, Bangladesh.

Received: 12 April 2020 Accepted: 13 October 2021

Published online: 29 October 2021

\section{References}

1. Islam MA, Ahmed MU, Begum N, Chowdhury NA, Khan AH, Parquet Mdel C, et al. Molecular characterization and clinical evaluation of dengue outbreak in 2002 in Bangladesh. Jpn J Infect Dis. 2006;59:85-91.

2. Biswas R, Mohammed FR, Sengupta P, Ahmed HS, Rahman MM, Sarker MAS, et al. Dengue NS1 antigen: a tool in early detection of dengue virus infection. J Med. 2014;15:28-30.

3. Akram A. Alarming turn of dengue fever in Dhaka City in 2019. Bangladesh J Infect Dis. 2019;6:1-2.

4. Sharmin S, Viennet E, Glass K, Harley D. The emergence of dengue in Bangladesh: epidemiology, challenges, and future disease risk. Trans $\mathrm{R}$ Soc Trop Med Hyg. 2015;109:619-27.

5. DGHS: Director General of Health Services. Daily daily status report. 2021. https://dghs.gov.bd/index.php/bd/home/ 5200-daily-dengue-status-report.

6. NEWS DESK. Bangladesh dengue cases top 1,000, down dramatically from 2019. 2020. http://outbreaknewstoday.com/bangladesh-denguecases-top-1000-down-dramatically-from-2019/.

7. Azad DAK, Ferdousic DS, Islam QT, et al. National guideline for clinical management of dengue syndrome. 4th ed. Dhaka: Government of the People's Republic of Bangladesh; 2018. https://doi.org/10.1017/CBO97 81107415324.004.

8. Pervin M, Tabassum S, Sil BK, Islam MN. Isolation and serotyping of dengue viruses by mosquito inoculation and cell culture technique: an experience in Bangladesh. Dengue Bull. 2003;27:81-90.

9. Kabir A, Abdullah AA, Sadeka MM, Ahmed H, Kahhar M. The impact of dengue on liver function as evaluated by aminotransferase levels. J Med. 2008;9:66-8.

10. Amhed MA, Ahmed MU, Begum N, Chowdhury NA, Khan AH, Parquet $M C$, et al. Molecular characterization and clinical evaluation of dengue outbreak in 2002 in Bangladesh. Jpn J Infect Dis. 2006;59:85-98.

11. Amin MR, Islam MR, Bhuiyya M, Hasan MJ, Islam MS, Islam F, et al. Clinical study on paradigm shift of dengue syndrome in Bangladesh-2018. Unpubl Work; unpublished.

12. Islam QT, Basher A, Amin R. Dengue: a practical experience of medical professionals in hospital. J Med. 2012;13:160-4.

13. Arif KM, Mohammed FR, Nur Z, Shams M, Alam M, Uddin M, Ahasan H. Clinical profile and outcome of dengue hemorrhagic fever in a Tertiary Care Hospital in Dhaka. J Med. 2009;10:12-5.

14. Mohammad H, Sarkar DN, Amin MR, Basher A, Ahmed T. Clinical profile and outcome of patients with dengue syndrome in hospital care. J Med. 2011;12:131-8.

15. Rahman M, Rahman K, Siddque AK, Shoma S, Kamal AH, Ali KS, et al. First outbreak of dengue hemorrhagic fever, Bangladesh. Emerg Infect Dis. 2002;8:738-40.

16. Alam ABMS, Sadat SA, Swapan Z, Ahmed A, Karim M, Paul H, et al. Clinical profile of dengue fever in children. Bangladesh J Child Health. 2009;33:55-8.

17. Shultana K, Rahman AZMM, Al Baki A, Khan MSI, Deb B, Chowdhury D, et al. Dengue infection in children: clinical profile and outcome in Dhaka City. Am J Pediatr. 2019:5:111.

18. Muraduzzaman AKM, Alam AN, Sultana S, Siddiqua M, Khan MH, Akram $A$, et al. Circulating dengue virus serotypes in Bangladesh from 2013 to 2016. VirusDisease. 2018;29:303-7. 
19. Shirin T, Muraduzzaman AKM, Alam AN, Sultana S, Siddiqua M, Khan MH, et al. Largest dengue outbreak of the decade with high fatality may be due to reemergence of DEN-3 serotype in Dhaka, Bangladesh, necessitating immediate public health attention. New Microbes New Infect. 2019;29:1-2.

20. Pervin M, Sweety AA, Hossain MZ, Sharmin R, Fatema N, Rahman MA, et al. Sero-epidemiology of dengue virus infection in clinically suspected patients attended in Dhaka Medical College Hospital during January to December 2016. J Dhaka Med Coll. 2018;26:111-6.

21. Sultana N, Fatema N, Hossain MZ, Rahman MA, Nehar N, Yeasmin MM, et al. Frequency of dengue infection in febrile patients attended Dhaka Medical College Hospital during January to December, 2018. J Dhaka Med Coll. 2020;28:105-11.

22. Dhaka Medical College Hospital, Dhaka, Bangladesh, Latitude and longitude coordinates. Retrieved from https://www.latlong.net/place/dhakabangladesh-718.html. Last Accessed 14 Apr 2020.

23. Health Bulletin 2018. Government of the People's Republic of Bangladesh, Ministry of the Health and Family welfare

24. Begum K. Analysis of 20,119 deliveries in Dhaka Medical College Hospital. Asia Ocean J Obstet Gynaecol. 1993;19(1):1-6. https://doi.org/10.1111/j. 1447-0756.1993.tb00339.x.

25. National guideline for clinical management of dengue syndrome. 4th ed. Dhaka: Government of the People's Republic of Bangladesh; 2018. pp. 1-87. https://dghs.gov.bd/images/docs/Guideline/National\%20Gui delinee\%20for\%20Clinical\%20Management\%20of\%20Dengue\%20Syn drome\%202018.pdf.

26. Mone FH, Hossain S, Hasan MT, Tajkia G, Ahmed F. Sustainable actions needed to mitigate dengue outbreak in Bangladesh. Lancet Infect Dis. 2019;19:1166-7.

27. Hasan S, Jamdar S, Alalowi M, Al Beaiji SM. Dengue virus: a global human threat: review of literature. J Int Soc Prev Community Dent. 2016;6(1):1.

28. Ahsan A, Haider N, Kock R, Benfield C. Possible drivers of the 2019 dengue outbreak in Bangladesh: the need for a robust community-level surveillance system. J Med Entomol. 2021;58(1):37-9.
29. Chen CH, Huang YC, Kuo KC, Li CC. Clinical features and dynamic ordinary laboratory tests differentiating dengue fever from other febrile illnesses in children. J Microbiol Immunol Infect. 2018;51:614-20.

30. Deshwal R, Qureshi MI, Singh R. Clinical and laboratory profile of dengue fever. J Assoc Physicians India. 2015;63:30-2.

31. Alvarado-Castro VM, Ramírez-Hernández E, Paredes-Solís S, Legorreta Soberanis J, Saldaña-Herrera VG, Salas-Franco LS, et al. Clinical profile of dengue and predictive severity variables among children at a secondary care hospital of Chilpancingo, Guerrero, Mexico: case series. Boletín Médico Del Hosp Infant México (English Ed). 2016;73:237-42.

32. Jain D, Rajput R, Pathak V, Mittal A, Jain P. Changing trends in clinical presentation and biochemical spectrum of dengue fever: an observation of a tertiary care centre. Arch Clin Infect Dis. 2017. https://doi.org/10.5812/ archcid.62221.

33. Sreenivasulu T, Jahnavi K. A study of clinical profile of patients with dengue fever at a tertiary care hospital. 2019;(July). https://www.ijmedicine. com/index.php/ijam/article/view/920.

34. Tewari K, Tewari V, Mehta R. Clinical and hematological profile of patients with dengue fever at a tertiary care hospital — an observational study. Mediterr J Hematol Infect Dis. 2018. https://doi.org/10.4084/mjhid. 2018.021.

35. Yung CF, Lee KS, Thein TL, Tan LK, Gan VC, Wong JGX, et al. Dengue serotype-specific differences in clinical manifestation, laboratory parameters and risk of severe disease in adults, Singapore. Am J Trop Med Hyg. 2015;92(5):999-1005.

36. Guzman MG, Kouri $G$. Dengue and dengue hemorrhagic fever in the Americas: lessons and challenges. J Clin Virol. 2003;27(1):1-13. https://doi. org/10.1016/s1386-6532(03)00010-6.

\section{Publisher's Note}

Springer Nature remains neutral with regard to jurisdictional claims in published maps and institutional affiliations.
Ready to submit your research? Choose BMC and benefit from:

- fast, convenient online submission

- thorough peer review by experienced researchers in your field

- rapid publication on acceptance

- support for research data, including large and complex data types

- gold Open Access which fosters wider collaboration and increased citations

- maximum visibility for your research: over $100 \mathrm{M}$ website views per year

At BMC, research is always in progress.

Learn more biomedcentral.com/submissions 